\title{
COVID-19: The Second Wave-Are There Lessons from the First Wave to Prepare Us for the Second Wave?
}

\author{
Anirudh Kohli ${ }^{1}$ \\ ${ }^{1}$ HOD, Department of Imaging, Breach Candy Hospital, Mumbai, \\ India
}

Indian J Radiol Imaging 2021;31:1-2.

It has been a year since we were exposed to a totally new disease. Now we are at the start of the second wave that historically has been more severe than the first wave. Are there any lessons to learn from the first wave that may help us reduce the impact of the second wave?

As the first wave progressed, it was discovered that severe acute respiratory syndrome coronavirus 2 (SARS-CoV-2) that causes coronavirus disease 2019 (COVID-19) pneumonia was different from its predecessor SARS-CoV-1. SARS-CoV-1 mainly occurred in symptomatic individuals. SARS-CoV-2 occurs in a large number of asymptomatic. ${ }^{1}$ These asymptomatic go undetected and act as super spreaders. A study done very early in the first wave on the Diamond Princess cruise ship revealed that 54\% of asymptomatic individuals with SARS-CoV-2 had positive computed tomography (CT) findings. ${ }^{2}$ This finding has subsequently been supported by numerous international and more importantly national researchers. ${ }^{3-10}$ Kashyape and Jain ${ }^{8}$ did an interesting study of 1,499 patients and divided them into two groups, symptomatic and asymptomatic. Interestingly the percentage of positive high-resolution computed tomography (HRCT) was similar irrespective of their symptoms, debunking the theory that asymptomatics have a very low percentage of positive imaging studies.

Another negative aspect discovered during the first wave was the high false negative rate of reverse transcription polymerase chain reaction (RT-PCR) (30-40\%). ${ }^{11}$ This means that individuals who are false negative can be super spreaders. Again, numerous international and national researchers have demonstrated HRCT positivity in individuals with negative RT-PCR. ${ }^{12-18}$ HRCT can help reduce false negative rate as well as curb super spreading of SARS-CoV-2. It is important to note that CT may be negative in a positive RT-PCR and vice versa. These tests are complementary and not competitive.

Artificial intelligence (AI) in medical imaging is a major buzzword as we enter the third decade of the twenty-first century. COVID-19 was a perfect testing ground for AI
Address for correspondence Anirudh Kohli, MD, DNB, DMRD, HOD Department of Imaging, Breach Candy Hospital, Mumbai 400026, India (e-mail: dranirudhkohli@gmail.com).

especially as it needed to concentrate on only two modalities, chest X-ray and CT scan. The findings were also fairly typical and specific of ground glass densities/consolidations in a subpleural/peribronchovascular location. Numerous articles have evaluated the performance of $\mathrm{AI}$ systems especially in India where the cohort of patients has been very high, all concluding the experienced radiologists performed better than the AI system in the detection of COVID-19 pneumonia. ${ }^{19-21}$

Where AI is making a significant impact is on the quantification of extent of lung involvement. In a pandemic, the main concern is as large volumes of patients present at the same time, medical facilities will get overwhelmed triggering panic and societal problems. Triage is needed to help determine rapidly where these patients will be managed so as to optimally utilize medical facilities as well as not overwhelm the medical facilities. It is also useful to determine when the patient needs to be admitted, whether in a ward or directly to intensive care unit (ICU), what oxygen requirements are envisaged, $\mathrm{O}_{2}$ by nasal canula, noninvasive ventilation, or invasive ventilation. Patients may also rapidly progress and this needs to be predicted. The extent of lung involvement is a good surrogate to detect disease burden; a low percentage of aerated lung correlates with a poor prognosis.

Several CT scoring systems have been proposed, 20, 25, 40,72 point scale as well as percentage of lung involvement. All these evaluate the extent of lung involvement depending upon the percentage of involvement of each lobe, based on the extent of involvement these are converted to points that are summed up to provide a final score. These scores are based on visual assumption; thus, this is a subjective method with significant inter- and intraobserver variation, resulting in significant under- and overestimation; there is no standardization. Additionally, this is a time-consuming process that does not help in a pandemic when there are numerous patients; quick accurate results are required to help triage these patients.
DOI https://doi.org/

10.1055/s-0041-1729668

ISSN 0971-3026
(C) 2021. Indian Radiological Association

This is an open access article published by Thieme under the terms of the Creative Commons Attribution-NonDerivative-NonCommercial-License, permitting copying and reproduction so long as the original work is given appropriate credit. Contents may not be used for commercial purposes, or adapted, remixed, transformed or built upon. (https://creativecommons.org/licenses/by-nc-nd/4.0/).

Thieme Medical and Scientific Publishers Private Ltd. A-12, Second Floor, Sector -2, NOIDA -201301, India 
A recent study utilizing AI system (pulmo density package ${ }^{22}$ that provided percentage of lung involvement was utilized in a large cohort of patients that demonstrated a significant correlation between extent of lung involvement and hospitalization, oxygen requirement, ICU, or ward admission.

Very early in the first wave various radiological societies and health organizations advised strongly against the utilization of CT in the detection of COVID-19 pneumonia caused by SARS-CoV-2. As the first wave progressed, the realization of the great value of $\mathrm{CT}$ in this pandemic unfolded, especially in countries like India where there is democratization in the utilization of imaging equipment, not controlled by national policies or insurance companies. In states like Maharashtra, the government realized the value of CT scan and controlled the price of scans between Rs 2000 and 3000 for HRCT. This made it easily accessible and affordable. The large cohort of patients in India resulted in numerous excellent studies on the role of HRCT in asymptomatic and negative RT-PCR. In fact, there has been no disease that has been imaged so much!

Understandably, there has been a call for a review of recommendations and guidelines issued by national and international societies on the utilization of CT scan in COVID-19 pneumonia.

In conclusion, two important lessons learned from the first wave are:

1. CT is very useful in the detection of COVID-19 in asymptomatic and/or RT-PCR-negative individuals. It has the added advantage of a very quick turnaround time as compared with RT-PCR. CT can play a previously undiscovered role as a public health tool to detect super spreaders early. The important point to remember CT may be negative in a positive RT-PCR individual and vice versa, so they are complementary investigations and not competitive.

2. CT is very useful in detecting the extent of lung involvement that helps triage/further management prognostication of individuals. AI is playing a strong role to accurately quantify the extent of disease removing subjectivity. Another important conclusion of the first wave is that $\mathrm{AI}$ at present will not be able to replace the experienced radiologists but will function as a useful ally.

\section{Conflict of Interest}

None declared.

\section{References}

1 Kohli A. Was non-utilisation of computed tomography as a public health tool a costly lapse in closing the pandemic? Indian J Radiol Imaging 2021;31(Suppl 1) :S1-S3

2 Inui $\mathrm{S}$, Fujikawa $\mathrm{A}$, Jitsu $\mathrm{M}$, et al. Chest $\mathrm{CT}$ findings in cases from the cruise ship "Diamond Princess" with coronavirus disease 2019 (COVID-19) Radiol Cardiothorac Imaging 2020;2(2):e204002

3 Ramanan RV, Joshi AR, Venkataramanan A, Nambi SP, Badhe R. Incidental chest computed tomography findings in asymptomatic Covid-19 patients. A multicentre Indian perspective. Indian J Radiol Imaging 2021;31(Suppl 1) :S45-S52

4 Shah SA, Gajbhiye MI, Saibannawar AS, Kulkarni MS, Misal UD, Gajbhiye DI. Retrospective analysis of chest HRCT findings in coronavirus disease pandemic (COVID-19)- an early experience. Indian J Radiol Imaging 2021;31(Suppl 1) :S101-S109

5 Sharma K, Gupta A, Vadgama K, et al. Demographic and clinico-radiological profile on high-resolution computerized tomography (HRCT) thorax in mild or asymptomatic clinically suspected COVID-19 patients in high-endemicity area of India-Can HRCT be the first screening tool? -The DECRYPTION study. Indian J Radiol Imaging 2021;31(Suppl 1) :S122-S127

6 Ravikanth R. Diagnostic accuracy and false-positive rate of chest CT as compared to RT-PCR in coronavirus disease 2019 (COVID-19) pneumonia: a prospective cohort of 612 cases from India and review of literature. Indian J Radiol Imaging 2021;31(Suppl 1) :S161-S169

7 Parry AH, Wani HA, Choh NA, Shah NN, Jehangir M. Spectrum of chest CT manifestations of coronavirus disease (COVID-19): a pictorial essay. Indian J Radiol Imaging 2021;31(Suppl 1) :S170-S177

8 Kashyape R, Jain R. The utility of HRCT in the initial diagnosis of COVID-19 pneumonia-an Indian perspective. Indian J Radiol Imaging 2021;31(Suppl 1) :S178-S181

9 Shah JV, Shah C, Shah S, et al. HRCT chest in COVID-19 patients: an initial experience from a private imaging center in western India. Indian J Radiol Imaging 2021;31(Suppl 1) :S182-S186

10 Rajalingam B. CT chest - a rapid screening tool in COVID-19 pandemic. Indian J Radiol Imaging 2021;31(Suppl 1) :S212-S213

11 Kohli A, Joshi A, Shah A, et al. Does CT help in reducing RT-PCR false negative rate for COVID-19? Indian J Radiol Imaging 2021;31(Suppl 1) :S80-S86

12 Gandhi M, Yokoe DS, Havlir DV. Asymptomatic transmission, the Achilles' heel of current strategies to control Covid-19. N Engl J Med 2020;382(22):2158-2160

13 Mizumoto K, Kagaya K, Zarebski A, Chowell G. Estimating the asymptomatic proportion of coronavirus disease 2019 (COVID-19) cases on board the Diamond Princess cruise ship, Yokohama, Japan, 2020. Euro Surveill 2020;25(10):2000180

14 prpt. Nishiura H, Kobayashi T, Miyama T, et al. Estimation of the asymptomatic ratio of novel coronavirusinfections (COVID-19)? medRxiv. 2020 doi: 10.1101/2020.02.03.20020248/prpt

15 Shi $\mathrm{H}$, Han X, Jiang N, et al. Radiological findings from 81 patients with COVID-19 pneumonia in Wuhan, China: a descriptive study. Lancet Infect Dis 2020;20(4):425-434

16 Kucirka LM, Lauer SA, Laeyendecker O, Boon D, Lessler J. Variation in false-negative rate of reverse transcriptase polymerase chain reaction-based SARS-CoV-2 tests by time since exposure. Ann Intern Med 2020;173(4):262-267

17 Xie X, Zhong Z, Zhao W, Zheng C, Wang F, Liu J. Chest CT for typical 2019-nCoV pneumonia: relationship to negative RT-PCR testing? Radiology 2020;•••10.1148/radiol.2020200343

18 Ai T, Yang Z, Hou H, et al. Correlation of chest CT and RT-PCR testing in coronavirus disease 2019 (COVID-19) in China: a report of 1014 cases. Radiology 2020;296(2):E32-E40

19 Pankhania M. Artificial intelligence and radiology: combating the COVID-19 conundrum. Indian J Radiol Imaging 2021;31(Suppl 1) :S4-S10

20 Krishnamoorthy S, Ramakrishnan S, Colaco LB, et al. Comparing a deep learning model's diagnostic performance to that of radiologists to detect Covid-19 features on chest radiographs. Indian J Radiol Imaging 2021;31(Suppl 1) :S53-S60

21 Sukhija A, Mahajan M, Joshi PC, Dsouza J, Seth ND, Patil KH. Radiographic findings in COVID-19: comparison between AI and radiologist. Indian J Radiol Imaging 2021;31(Suppl 1) :S87-S93

22 Kohli A, Jha T, Pazhayattil AB. The value of AI based CT severity scoring system in triage of patients with Covid-19 pneumonia as regards oxygen requirement and place of admission. Indian J Radiol Imaging 2021;31(Suppl 1) :S61-S69 